\title{
Mystus ngasep, a new catfish species (Teleostei: Bagridae) from the headwaters of Chindwin drainage in Manipur, India
}

\author{
A. Darshan ${ }^{1}$, W. Vishwanath ${ }^{2}$, P.C. Mahanta ${ }^{3} \&$ A. Barat ${ }^{4}$ \\ 1,3,4 Directorate of Coldwater Fisheries Research, Bhimtal, Nainital, Uttarakhand 263136, India \\ ${ }^{2}$ Department of Life Sciences, Manipur University, Canchipur, Manipur 795003, India \\ Email: ${ }^{1}$ achom_darshan@yahoo.com; ${ }^{2}$ wvnath@gmail.com (corresponding author), ${ }^{3}$ director@dcfr.res.in; ${ }^{4}$ abarat58@hotmail.com
}

Date of publication (online): 26 November 2011 Date of publication (print): 26 November 2011 ISSN $0974-7907$ (online) | 0974-7893 (print)

Editor: Carl Ferraris

\section{Manuscript details:}

Ms \# 02180

Received 16 April 2009

Final received 05 September 2011

Finally accepted 07 November 2011

Citation: Darshan, A., W. Vishwanath, P.C. Mahanta \& A. Barat (2011). Mystus ngasep a new catfish species (Teleostei: Bagridae) from the headwaters of Chindwin drainage in Manipur, India. Journal of Threatened Taxa 3(11): 2177-2183.

Copyright: () A. Darshan, W. Vishwanath, P.C. Mahanta \& A. Barat 2011. Creative Commons Attribution 3.0 Unported License. JoTT allows unrestricted use of this article in any medium for non-profit purposes, reproduction and distribution by providing adequate credit to the authors and the source of publication.

For Author Details and Author Contribution see end of this article

Acknowledgements: We are thankful to Heok Hee $\mathrm{Ng}$ for providing us valuable literature required for this study. The first author is grateful to Department of Biotechnology, Government of India for awarding fellowship under DBTPostdoctoral program in Biotechnology and Life Sciences.
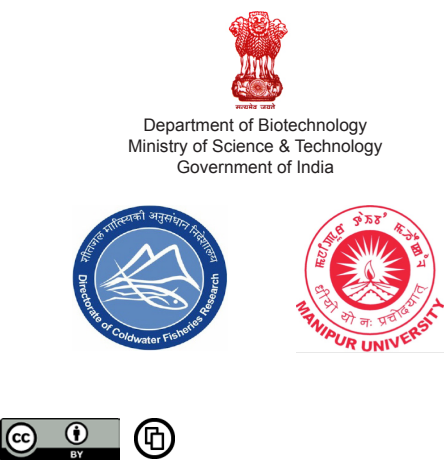

OPEN ACCESS | FREE DOWNLOAD
Abstract: Mystus ngasep, a new species of bagrid catfish from the headwaters of Chindwin drainage in Manipur, India, is described here. It is distinguished from its congeners in having a unique combination of the following characters: a colour pattern of the body consisting of a distinct dark tympanic spot and three brown stripes separated by pale narrow longitudinal lines, cranial fontanel reaching the base of the occipital process, a long-based adipose fin contacting the base of the last dorsal-fin ray anteriorly, 16-19 gill rakers on the first branchial arch, a slender cleithral process, pectoral spine with 9-11 serrations on the posterior edge, eye with a diameter of $16.5-19.8 \% \mathrm{HL}$ and prepectoral length 22.2-26.0 \% SL. The new species has been compared with its congeners from Myanmar and also from northeastern India.

Keywords: Chindwin headwater, Mystus, new catfish.

\section{INTRODUCTION}

Fishes of the genus Mystus Scopoli are small to medium-sized bagrid catfishes occurring in South Asia. Roberts (1994) recognized Mystus to have an elongate cranial fontanel reaching up to the base of the occipital process, long maxillary barbel, very long adipose fin, 11-30 gill rakers on the first gill arch and 37-46 total vertebrae, about equally divided between abdominal and caudal regions. He included only eight species under the genus. Mo (1991) characterized the genus to have a thin needle-like first infraorbital, twisted and thickened metapterygoid loosely attached to the quadrate by means of ligament or a small extent of cartilage. Jayaram \& Sanyal (2003) and Ferraris (2007) respectively listed 44 and 33 species of Mystus as valid.

Manipur State in the northeastern corner of India has two headwaters: that of the Brahmaputra basin in the west and of the Chindwin in the east. Hora (1921) reported Mystus bleekeri from the lakes and streams of Manipur Valley, including the Loktak Lake (all headwaters of the Chindwin River drainage). Hora (1936) also collected the species from the Brahmaputra basin in Nagaland and Menon (1954) from Manipur. The species was also reported from the Chindwin basin of Manipur by Menon (1953, 1954), Singh \& Singh (1985), Vishwanath et al. (1998), Arunkumar \& Singh (1997) and Vishwanath (2000).

Other known species of Mystus from the neighboring Myanmar, also drained by the Chindwin-Irrawaddy are: Mystus cineraceus, M. gulio, M. falcarius, M. leucophasis, M. pulcher and M. rufescens (Ng \& Kottelat 2009). The Ganga-Brahmaputra basin in northeastern India has M. bleekeri, M. dibrugarensis, M. tengara, M. cavasius and M. carcio 
(Vishwanath et al. 2007; Darshan et al. 2010).

Present studies reveal that the species of Mystus occurring abundantly in the streams, rivers and lakes (all belonging to the Chindwin drainage) in the valley of Manipur are without a name and the species has been misidentified as M. bleekeri after Hora (1921). The species is herein described as Mystus ngasep sp. nov.

\section{MATERIAL AND METHODS}

Materials examined are deposited in the Manipur University Museum ofFishes(MUMF). Measurements were made with a dial caliper to the nearest $0.1 \mathrm{~mm}$. Body proportions were expressed in percentage of SL and HL. Counts and measurements follow those of $\mathrm{Ng} \&$ Dodson (1999). Dorsal fin height was measured from the base of the spinelet to the highest point of the dorsal fin. For osteological studies, clearing and staining techniques follow Hollister (1934). Methods for counting gill rakers and vertebrae follow Roberts (1992) and Roberts (1994), respectively.

\section{Mystus ngasep sp. nov. (Image 1, Fig. 1, Table 1)}

Macrones bleekeri Hora, 1921: 165-214 (brief description of specimens from Manipur valley, Chindwin basin).

Mystus bleekeri Menon, 1953: 266 (listed from Manipur valley); Menon, 1954: 22 (in part, listed from Manipur valley); Singh \& Singh, 1985: 87 (reported from Sekmai \& Chakpi Rivers, Manipur); Vishwanath et al. 1998: 323 (reported from Chatrikong River,
Manipur); Arunkumar \& Singh, 1997: 131 (reported from Yu-River in Manipur); Jayaram \& Sanyal, 2003: 42 (in part, synonymy and description).

\section{Material examined:}

Holotype: 10.xii.2007, 98.3mm SL, 24048'N 93055'E, Nambul River at Bijoygovinda-Polemleikai Bridge, Chindwin-Irrawaddy drainage, Manipur State, India, A. Darshan (MUMF 9500).

Paratypes: 4 ex., ii.2008, 96.5-103.0 mm SL; data as for holotype (MUMF 9501/1-9501/4); 12.viii.2000, 7ex., 87.0-71.6 mm SL, Wangoi-Ngarian Lake, (Chindwin drainage), A. Drashan (MUMF 9502/19502/7); 08.ix.2000, 4 ex., 79.9-108.7 mm SL, Khuga River (Chindwin drainage), Churanchanpur District, K. Santa Devi (MUMF 9503/1-9503/4); 02.xi.2006, 14 ex., 60.5-86.3 mm SL, Nambul River at Naoremthong, Imphal-west District, H. Joyshree Devi, (MUMF 9504/1-9504/14).

Non-type material: 16.v.2001, 22 ex., 70.2-96.2
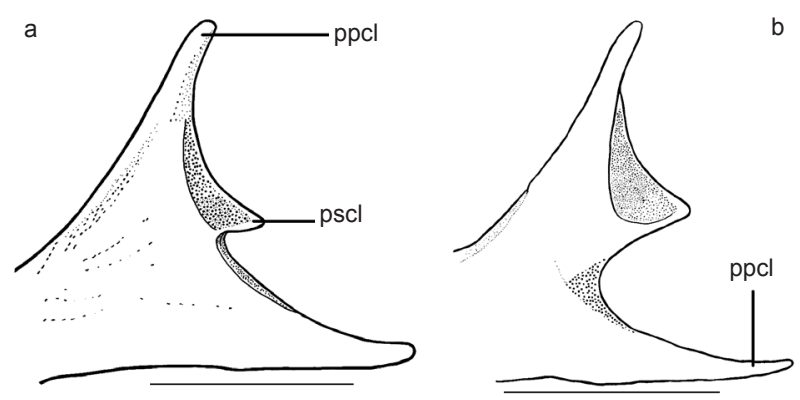

Figure1. Lateral views of cleithral process. a - Mystus bleekeri (MUMF 9521) 90.8mm SL; b - Mystus ngasep sp. nov. (MUMF 9501) paratype, $98.5 \mathrm{~mm}$ SL. $\mathrm{dpcl}$ - dorsal process of cleithrum for articulation with posttemporal; pscl - posterodorsal spine of cleithrum; $\mathrm{ppcl}$ - posterior process of cleithrum. scale bar $=5 \mathrm{~mm}$

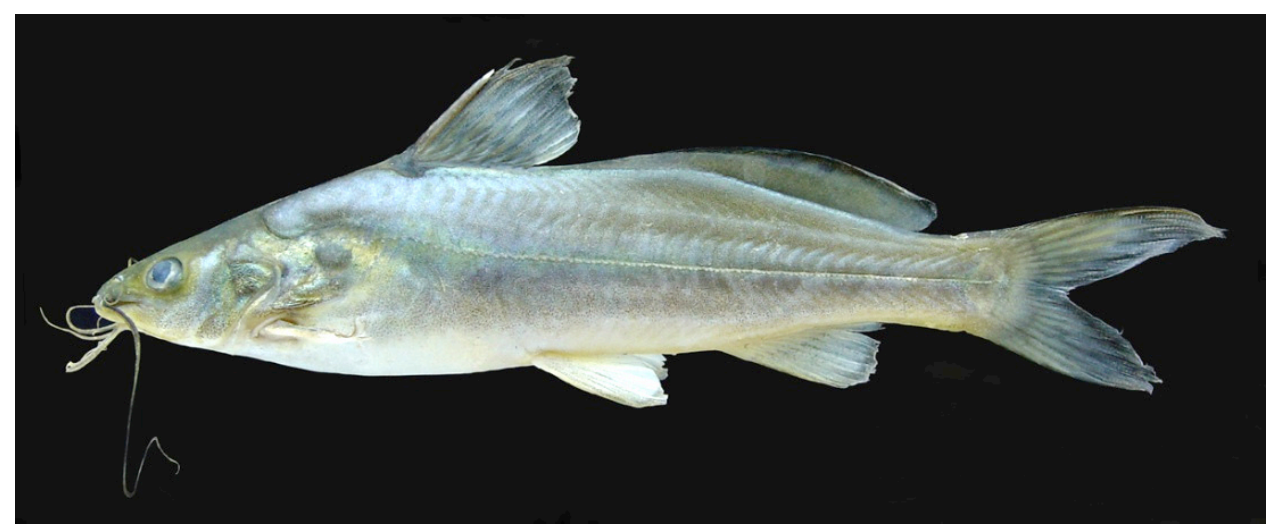

Image 1. Mystus ngasep sp. nov. (MUMF 9501/1) paratype, $96.5 \mathrm{~mm} \mathrm{SL}$. 
Table 1. Morphometric data of Mystus ngasep sp. nov.

\begin{tabular}{|c|c|c|c|}
\hline & Holotype & Range & Mean $\pm S D$ \\
\hline \multicolumn{4}{|l|}{ in $\% \mathrm{SL}$} \\
\hline Predorsal length & 37.7 & $37.0-41.4$ & $39.0 \pm 1.2$ \\
\hline Preanal length & 71.1 & $68.3-73.3$ & $70.4 \pm 1.3$ \\
\hline Prepelvic length & 48.3 & $47.1-51.9$ & $49.3 \pm 1.4$ \\
\hline Prepectoral length & 22.3 & $22.2-26.0$ & $23.3 \pm 1.2$ \\
\hline Height of dorsal fin & 20.8 & $20.8-21.8$ & $21.3 \pm 0.7$ \\
\hline Length of dorsal-fin base & 13.1 & $12.4-14.5$ & $13.2 \pm 0.7$ \\
\hline Dorsal-spine length & 13.3 & $12.2-15.5$ & $13.5 \pm 0.9$ \\
\hline Anal-fin length & 16.9 & $16.9-19.3$ & $18.2 \pm 0.9$ \\
\hline Pelvic-fin length & 13.9 & $13.0-16.3$ & $15.1 \pm 1.1$ \\
\hline Pectoral-fin length & 13.9 & $13.9-19.8$ & $17.6 \pm 1.9$ \\
\hline Pectoral-spine length & 13.4 & $11.8-15.3$ & $13.5 \pm 1.0$ \\
\hline Caudal-fin length & 25.9 & 23.0-26.9 & $25.2 \pm 1.2$ \\
\hline Length of adipose-fin base & 41.2 & $37.1-44.5$ & $41.0 \pm 1.8$ \\
\hline Adipose maximum height & 6.2 & $4.4-7.0$ & $5.9 \pm 0.7$ \\
\hline Post-adipose distance & 9.9 & $8.9-10.9$ & $9.7 \pm 0.6$ \\
\hline Caudal-peduncle length & 19.5 & $17.9-21.4$ & $19.4 \pm 1.1$ \\
\hline Caudal-peduncle depth & 10.8 & $9.2-10.8$ & $10.1 \pm 0.5$ \\
\hline Body depth at anus & 21.9 & $19.2-23.2$ & $20.8 \pm 1.2$ \\
\hline Head length & 25.1 & $24.6-28.6$ & $26.4 \pm 1.3$ \\
\hline Head width & 16.3 & $15.7-18.3$ & $16.9 \pm 0.8$ \\
\hline Head depth & 17.3 & $16.7-18.4$ & $17.6 \pm 0.6$ \\
\hline \multicolumn{4}{|l|}{ In \% HL } \\
\hline Snout length & 39.7 & $33.8-40.7$ & $37.8 \pm 1.6$ \\
\hline Eye diameter & 19.8 & $16.2-19.8$ & $18.2 \pm 1.3$ \\
\hline Interorbital distance & 30.7 & $30.3-31.8$ & $30.9 \pm 0.6$ \\
\hline Nasal-barbel length & 51.4 & $32.8-51.4$ & $45.5 \pm 6.2$ \\
\hline Maxillary-barbel length & 200.0 & $\begin{array}{c}200.0- \\
235.0\end{array}$ & $215.4 \pm 9.7$ \\
\hline $\begin{array}{l}\text { Inner mandibular-barbel } \\
\text { length }\end{array}$ & 66.4 & $58.6-76.0$ & $67.5 \pm 5.8$ \\
\hline $\begin{array}{l}\text { Outer mandibular-barbel } \\
\text { length }\end{array}$ & 101.2 & $\begin{array}{l}94.7- \\
118.6\end{array}$ & $106.3 \pm 8.6$ \\
\hline
\end{tabular}

mm SL, Iril River at Keibi (Chindwin River drainage), I. Linthoingambi, (MUMF 9505/1-9505/22); 06.vi.1996, 4 ex., 83.1-104.7 mm SL, Chatrickong River at Sanalok (Chindwin River drainage), Ukhrul District, K. Selim (MUMF 1096-1099).

\section{Diagnosis}

Mystus ngasep sp. nov. can be distinguished from congeners in having a unique combination of the following characters: a colour pattern consisting of a distinct dark tympanic spot and three brown stripes separated by pale narrow longitudinal lines on the sides of the body, cranial fontanel reaching the base of the occipital process, a long-based adipose fin contacting the base of the last dorsal-fin ray anteriorly, 16-19 gill rakers on the first branchial arch, a slender cleithral process (Fig. 1), pectoral spine with 9-11 serrations on the posterior edge, eye small with its diameter 16.5$19.8 \% \mathrm{HL}$, pectoral and anal fins with 9-10 and 8-9 branched rays respectively and short maxillary barbel (200.0-235.0\% HL).

\section{Description}

Morphometric data are shown in Table 1. Dorsal profile rising evenly (at an angle of $20-25^{\circ}$ to the horizontal) from tip of snout to origin of dorsal fin then goes almost horizontal to anterior third of adipose fin, then sloping gradually ventrally from there to end of caudal peduncle. Ventral profile roughly straight to end of anal-fin base, then sloping gently dorsally to the end of caudal peduncle.

Head depressed. Skin covering on dorsal surface of head thin. Anterior cranial fontanel extending from level of posterior nasal opening to posterior orbital margins, separated from posterior fontanel by epiphyseal bar. Posterior fontanel extends to the base of the supraoccipital process. Supraoccipital process long, reaching basal bone of dorsal fin, its base narrow with about one-fifth of its length, distally tapered. Eye ovoid, horizontal axis longest, located entirely in the dorsal half of the head.

Mouth sub-terminal. Oral teeth small and villiform, arranged in irregular rows. Premaxillary tooth band slightly curved backward, of equal width throughout. Tooth band on vomer continuous across midline and crescentic, slightly broader than premaxillary in middle, tapering posterolaterally, extending to level of lateral end of premaxillary tooth band. Dentary tooth band separated in the middle by thick skin, tapering laterally on each side, broader than premaxillary and vomerine tooth band at symphysis, length of one side equals lateral span of vomerine tooth band. Gill openings wide, free from isthmus. First branchial arch has 16-19 gill rakers.

Barbels in four pairs, maxillary barbel not reaching anal-fin origin, nasal reaching posterior rim of eye, outer mandibular barbel reaching base of pectoral fin and inner mandibular barbel slightly shorter. Skin smooth. Lateral line complete and midlateral in position. 
Dorsal-fin origin slightly anterior to the middle of the body, with spinelet, spine, and seven branched rays. Dorsal spine three-fifths to three-fourths of dorsal-fin height, smooth on both edges. Adipose fin long, spanning most of postdorsal distance, its origin in contact with base of last dorsal-fin ray and deeply incised posterior portion. Pectoral fin with I, 9-10 rays, fin margin straight posteriorly. Pectoral spine backwardly curved with 9-11 large posterior serrations and anteriorly rough. Pelvic fin short with i,5 rays. Anal-fin origin inserted at vertical through middle of adipose-fin base, with iii-v, 8-9 rays, anterior two simple rays minute, visible in alizarin stained specimens. Caudal fin deeply forked with i,7,8,i rays, upper lobe longer.

Osteological characters: Ribs: commonly 12 , rarely 11 ; vertebra with $40-41 \quad(21+19=40$ or $22+18=40$ or $23+18=41$ ). Haemal arches closed to form haemal canal from the 12th-14th vertebrae onwards. Branchiostegal with nine rays. Caudal skeleton composed of five hypural plates (two on lower and three on upper lobe). Parhypural free from first hypural plate. Hypurapophysis and secondary hypurapophysis fused. Epural laterally flattened and curved backward. Dorsal and ventral lobes of caudal fin with 10 and 11 Procurrent rays, respectively.

Sexual dimorphism: Males with long genital papilla reaching to the base of the second branched anal-fin ray. Females with rounded genital opening.

Colour: In life or freshly dead: dorsal portion of the head and body brownish-grey with greenish reflection; tympanic spot without distinct margin, with greenish reflection that is more pronounced in the middle; lateral surface of body silvery with brownishgolden reflection without prominent stripes, ventrally dull white.

In $10 \%$ formalin: dorsal portion of the head and body brownish-gray, tympanic spot with distinct margin, three brown lateral stripes on body separated by pale longitudinal lines, lower pale longitudinal line about twice as wide as the upper. Caudal-fin base without dark spot.

\section{Etymology}

The specific epithet is derived from the Manipuri local name of the fish: 'Ngasep'.

\section{Distribution}

Presently known from the Loktak Lake, Nambul, Manipur, Iril, Imphal, Thoubal, Khuga rivers and the tributaries of the Yu river (all belonging to the Chindwin River drainage) in Manipur.

\section{DISCUSSION}

$\mathrm{Ng} \&$ Kottelat (2009) clarified the identity of Mystus bleekeri and restricted its distribution to the GangaBrahmaputra basin while M. rufescens was found to be limited to the Irrawaddy basin. Their conclusion was based on the very distant geographical origins of the type series of $M$. bleekeri (Sind, Yamuna, upper waters of Ganga and Burma) which predicted involvement of more than one species; Day's (1877) observation of a black spot at the base of the caudal fin in the Burmese specimens and Roberts's (1994) reference of Day's type material from Burma as M. rufescens.

As mentioned earlier, six congeners of Mystus ngasep sp. nov. are known from Myanmar. Among those, $M$. cineraceus, $M$. rufescens and $M$. falcarius are very similar to the new species in having a long-based adipose fin that contacts the base of the last dorsal-fin ray anteriorly and cranial fontanel reaching to the base of the occipital process. A diagnostic summary of the species of Mystus from the Chindwin-Irrawaddy and Ganga-Brahmaputra River drainages is given in Table 2.

The new species differs from Mystus cineraceus in having three brown stripes on the body separated by pale narrow longitudinal lines above and below the lateral line (vs. a brownish body with a midlateral stripe lacking the pale longitudinal lines). It further differs from M. cineraceus in having more gill rakers on the first branchial arch (16-19 vs. 13-15; Table 3 ), more pectoral-fin rays (9-10 vs. 7-8), more analfin rays (8-9 vs. 6-7) and a shorter maxillary barbel (200.0-235.0 \% HL vs. 247.4-345.0).

Specimens of Mystus rufescens collected from the Chindwin basin in the Indo-Burma border in Manipur were examined and found to have a long-based adipose fin contacting the base of the last dorsal-fin ray anteriorly, a cranial fontanel reaching the base of the occipital process and a black spot at the base of the caudal fin. Vinciguerra's (1890) description of the species clearly states the presence of a black spot at 
Table 2. Key diagnostic characters of Mystus with a long adipose-fin base, distributed in the Chindwin-Irrawaddy and Ganga-Brahmaputra River drainage.

\begin{tabular}{|c|c|c|c|c|c|c|}
\hline & M. cineraceus & $\begin{array}{l}\text { M. ngasep } \\
\text { sp. nov. }\end{array}$ & M. falcarius & M. rufescens & M. bleekeri & M. cavasius \\
\hline Pectoral-fin rays & $7-8$ & $9-10$ & $7-10$ & $7-9$ & $9-10$ & $6-10$ \\
\hline Gill rakers & $13-15$ & $16-19$ & $22-29$ & $14-18$ & $11-15$ & $13-22$ \\
\hline Anal-fin rays & $6-7$ & $8-9$ & $6-9$ & $7-9$ & $8-9$ & $6-9$ \\
\hline Anal-fin length * & $10-13.4$ & $16.9-19.3$ & $9.8-11.5$ & - & $15.7-19.7$ & $9.3-12.4$ \\
\hline Eye diameter ** & $19.2-25.4$ & $16.2-19.8$ & $22.4-30.2$ & $20.8-23.5$ & $20.2-25.9$ & $21.2-32.7$ \\
\hline Maxillary-barbel length ${ }^{* *}$ & $247.4-345$ & $200-235$ & $435.6-538$ & $255.3-290.2$ & 241.3-330 & $355.8-504.9$ \\
\hline Humeral spot & absent & absent & $\begin{array}{c}\text { present as } \\
\text { crescent shape }\end{array}$ & absent & absent & $\begin{array}{l}\text { present as } \\
\text { ovoid shape }\end{array}$ \\
\hline Black spot at caudal-fin base & absent & absent & absent & present & absent & absent \\
\hline Nuchal spot & absent & absent & $\begin{array}{l}\text { present very } \\
\text { prominently }\end{array}$ & absent & absent & $\begin{array}{l}\text { present but } \\
\text { faint }\end{array}$ \\
\hline
\end{tabular}

* - as \% SL; ** - as \% HL

Table 3. Frequencies of gill rakers count in four species of Mystus with a long adipose fin distributed in the ChindwinIrrawaddy River drainage.

\begin{tabular}{|c|c|c|c|c|c|c|c|c|c|c|c|c|c|c|c|c|c|}
\hline & \multicolumn{17}{|c|}{ Total numbers of gill rakers on the first branchial arch } \\
\hline & 13 & 14 & 15 & 16 & 17 & 18 & 19 & 20 & 21 & 22 & 23 & 24 & 25 & 26 & 27 & 28 & 29 \\
\hline Species & & & & & & & & & & & & & & & & & \\
\hline M. cineraceus & 6 & 3 & 3 & & & & & & & & & & & & & & \\
\hline M. ngasep sp. nov. & & & & 5 & 21 & 18 & 11 & & & & & & & & & & \\
\hline M. rufescens & & 1 & 2 & 1 & & 1 & & & & & & & & & & & \\
\hline M. falcarius & & & & & & & & & & 9 & 7 & 5 & 5 & 1 & 1 & & 1 \\
\hline
\end{tabular}

the base of the caudal fin. We have also examined a syntype of M. bleekeri, labelled as ZSI 781, collected from Prome (=Pyay), Myanmar. The ZSI specimen has all the diagnostic characters of $M$. rufescens and also bears a noticeably darker region at the base of the caudal fin. The new species can be easily differentiated from $M$. rufescens by the absence of a black or dark brown spot at the base of the caudal fin (vs. spot present; Image 2), shorter maxillary barbel (200.0-235.0 \% HL vs. 255.3-290.2) and smaller eye (eye diameter: 16.2-19.8 \% HL vs. 20.8-23.5).

Mystus ngasep sp. nov. differs from M. falcarius and $M$. cavasius in having (vs. lacking) brown lateral stripes on the body, a shorter maxillary barbel (200.0 $235.0 \%$ HL vs. 355.8-538.0), a lower dorsal fin (dorsal-fin height: 20.8-21.8 \% SL vs. 25.7-33.6) and lacking the black spot in front of dorsal spine (vs. spot present).

Mystus ngasep sp. nov. differs from M. leucophasis and $M$. pulcher in having a longer cranial fontanel reaching the base of the occipital process (vs. not reaching, but extending up to half the length of supraoccipital bone); adipose-fin base in contact (vs. not in contact) with the base of the last dorsalfin ray anteriorly, and a smooth (vs. serrated) dorsal spine. Mystus leucophasis further differs from the new species in having (vs. lacking) a filamentous extension of the upper principle-ray of the caudal fin. M. ngasep sp. nov. further differs from M. pulcher in having a wider vomerine tooth-band (as wide as the premaxillary tooth-band vs. about one-third of the premaxillary tooth-band), fewer vertebrae (41-42 vs. 35) and lacking (vs. having) a black spot at the base of the caudal fin.

Jayaram \& Sanyal (2003) reported Mystus armatus from Manipur based on five specimens (92.2-125.6 $\mathrm{mm} \mathrm{SL}$ ), but they did not provide the exact collection site of the specimens. Ng \& Kottelat (2009) found no evidence that $M$. armatus is known from the Irrawaddy River drainage and also suggested that Jayaram \& Sanyal's (2003) specimens of M. armatus from Manipur might be a misidentification of $M$. cineraceus. We feel that Jayaram \& Sanyal (2003) might have misidentified specimens of M. rufescens as 


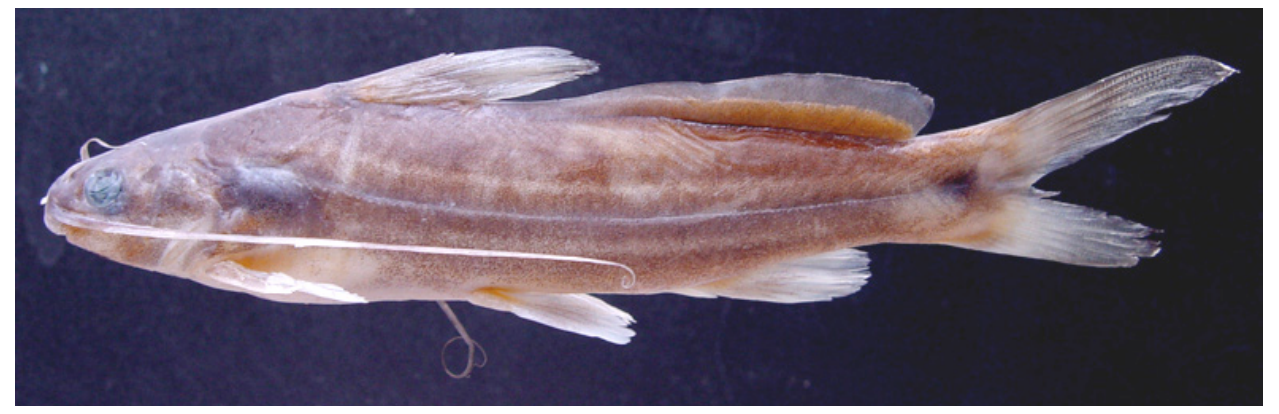

Image 2. Mystus rufescens (MUMF 9530) 101.1mm SL.

M. armatus, because $M$. armatus also possess a black spot at the base of the caudal fin also present in $M$. rufescens. We have also not encountered any species of Mystus with a black spot at the base of the caudal fin from our extensive surveys of the Brahmaputra River drainage in Manipur. However, we were unable to verify the identity of Jayaram \& Sanyal's (2003) material, as we were unable to locate this material for study in the collections of the Zoological Survey of India in Kolkata. Jayaram \& Sanyal (2003) also misidentified several specimens collected from the Chindwin River drainage in Manipur (ZSI 4236/2, ZSI F 4293/2, ZSI F 4346/2) as M. bleekeri. Mystus ngasep sp. nov. is very similar in colouration and meristic counts to M. bleekeri. However, the new species differs from $M$. bleekeri in having a slender (vs. broad) cleithral process, smaller eye (diameter 16.2-19.8 \% HL vs. 20.2-25.9), shorter maxillary barbel (200.0-235.0 \% HL vs. 241.3-330.0), more gill rakers on the first branchial arch (16-19 vs. 11-15), fewer pectoral spine serrations on the posterior edge (9-11 vs. 11-16) and longer prepectoral length (22.2$26.0 \%$ SL vs. 19.5-21.8) and dorsal spine that extends to about three-fifths to three-quarters (vs. nearly half) of the fin height. It further differs from M. bleekeri in having a narrower base of the supraoccipital process, its width at the base being about one-fifth of its length (vs. two-fifths to half of its length); more vertebrae (40-41 vs. 37-40), with the closure of the haemal arches appearing from the $12^{\text {th }}-14^{\text {th }}$ (vs. commonly $11^{\text {th }}$ or rarely $\left.12^{\text {th }}\right)$ vertebra onwards.

Mystus ngasep differs from $M$. dibrugarensis in having fewer gill rakers (16-19 vs. 28) on the first arch, more vertebrae (40-41 vs. 36 ), the absence (vs. presence) of a thin black mid-lateral line connecting the tympanic spot and the black spot at the base of the caudal fin. It differs from $M$. tengara in having a smooth (vs. with 8-9 serrations posteriorly) dorsal spine, longer adipose-fin base (37.1-44.5\% SL vs. 24.0-31.7), fewer gill rakers on the first arch (16-19 vs. 31-42), 11-12 (vs. 8-9) ribs and 40-41 (vs. 34-37) vertebrae.

Mystus ngasep sp. nov. differs from $M$. carcio in having more vertebrae (40-41 vs. 32), a longer adiposefin base (37.1-44.5\% SL vs. 8.5-11.9), vomerine tooth-band continuous (vs. interrupted in the middle), fewer gill rakers on the first arch (16-19 vs. 23-24) and lacking (vs. having) the coracoid shield below the pectoral fin. It differs from M. gulio in having a longer occipital process (reaching to the basal bone of dorsal fin vs. not reaching), origin of adipose-fin base in contact (vs. not in contact) with the base of the last dorsal-fin ray, and a smooth (vs. posteriorly serrated) dorsal spine.

\section{Comparative material}

Mystus bleekeri: ZSI Kolkata 1076 (lectotype), 101.5mm SL; India: Yamuna River.

MUMF 9521 (10), 85.6-108.3 mm SL; India: Ganga River at Patna. MUMF 9522 (10), 74.2-98.8 mm SL; India: Guwahati: Brahmaputra River.

Mystus rufescens: ZSI Kolkata 781 (1) [syntype of M. bleekeri], 95mm SL; Burma: Prome. MUMF 9530 (5), 84.5-101.1 mm SL; India: Manipur: Chandel district, Moreh market.

Mystus cavasius: MUMF 9513 (10), 74.8-109.7 mm SL; India: Guwahati: Brahmaputra River.

Mystus falcarius: MUMF 9514 and 9517 (9), 96.5-206 mm SL; India: Manipur: Lokchao River. Data of Chakrabarty \& Ng (2005) are also used for comparison.

Mystus pulcher: ZSI Kolkata F 4716-19/1 (4 syntypes), 51.7-55.5 mm SL; Burma: Bhamo. MUMF 1100-1105 (6), 55.8-69.9 mm SL; India: Manipur: Ukhrul District: Chatrikong River (headwater of Chindwin River drainage). 
Mystus tengara: MUMF 9520/1-9520/20 (20), 67.9-75.7 mm SL; India: West Bengal: Kolkata. MUMF 9523 (15), 52.1-77.5 mm SL; India: Brahmaputra River at Guwahati.

Mystus carcio: ZSI FF4081 (1), 47.9mm SL; India: Assam: Brahmaputra River at Guwahati. ZSI FF4080 (1), 42.9mm SL; same data as above. MUMF 9518/1 (1), 39.0mm SL; India: Assam: Brahmaputra River at Guwahati. MUMF 9518/3-9518/10 (8), 30.2-47.9 mm SL; same data as above. MUMF 9519/1-9519/17 (17), 39.0-47.0 mm SL; same data as above. MUMF 9531 (1), 36 mm SL; India: Assam: Ujan Bazar, Guwahati. Mystus leucophasis and M. gulio: Data of Jayaram \& Sanyal (2003).

\section{M. cineraceus: Data of $\mathrm{Ng} \&$ Kottelat (2009).}

\section{REFERENCES}

Arunkumar, L. \& H.T. Singh (1997). On the collection of fishes from the head-waters of Yu-River system with four new records in Manipur. Journal of Freshwater Biology 9(3-4): $126-133$.

Chakrabarty, P. \& H.H. Ng (2005). The identity of catfishes identified as Mystus cavasius (Hamilton, 1822) (Teleostei: Bagridae), with a description of a new species from Myanmar. Zootaxa 1093: 1-24.

Darshan, A., N. Anganthoibi \& W. Vishwanath (2010). Redescription of the Striped Catfish Mystus carcio (Hamilton) (Siluriformes: Bagridae). Zootaxa 2475: 48-54.

Day, F. (1875-78). The Fishes of India; Being A Natural History of the Fishes Known to Inhabit the Seas and Fresh Waters of India, Burma, and Ceylon. Bernard Quaritch, London, $778 \mathrm{pp}+195 \mathrm{pls}$.

Ferraris, C.J. Jr. (2007). Checklist of catfishes, recent and fossil (Osteichthyes: Siluriformes) and catalogue of Siluriform primary types. Zootaxa 1418: 1-628.

Hollister, G. (1934). Clearing and dying fishes for bone study. Zoologica 12: 89-101.

Hora, S.L. (1921). Fish and fisheries of Manipur with some observations on those of the Naga Hills. Records of the Indian Museum 22: 165-214.

Hora, S.L. (1936). On a further collection of fish from the Naga Hills. Records of the Indian Museum 38: 317-331.

Jayaram, K.C. \& A. Sanyal (2003). A taxonomic revision of the fishes of the genus Mystus Scopoli (Family: Bagridae). Records of the Zoological Survey of India, Occasional Paper 207: 1-136.

Menon, A.G.K. (1954). Further observations on the fish fauna of the Manipur State. Records of the Indian Museum 53: 21-26.

Menon, M.A.S. (1953). On a small collection of fish from Manipur, Assam. Records of Indian Museum 50: 265-270.

Mo, T.P. (1991). Anatomy, relationships and systematics of the
Bagridae (Teleostei: Siluroidei) with a hypothesis of siluroid phylogeny. Theses Zoologicae 17: 1-216.

Ng, H.H. \& J.J. Dodson (1999). Morphological and genetic descriptions of a new species of catfish, Hemibagrus chrysops, from Sarawak, East Malaysia, with an assessment of phylogenetic relationships (Teleostei: Bagridae).The Raffles Bulletin of Zoology 47: 45-57.

Ng, H.H. \& M. Kottelat (2009). A new species of Mystus from Myanmar (Siluriformes: Bagridae). Copeia 2009 (2): 245250.

Roberts, T.R. (1992). Revision of the striped catfishes of Thailand misidentified as Mystus vittatus, with descriptions of two new species (Pisces: Bagridae). Ichthyological Exploration of Freshwaters 3: 77-88.

Roberts, T.R. (1994). Systematic revision of Asian bagrid catfishes of the genus Mystus sensu stricto, with a new species from Thailand and Cambodia. Ichthyological Exploration of Freshwaters 5: 241-256.

Singh, W.V. \& H.T. Singh (1985). On the collection of fishes from Tengnoupal District of Manipur with some new records. International Journal of Ichthyology (Proc. V. AISI) 6: 85-90.

Vinciguerra, D. (1890). Viaggio di Leonardo Fea in Birmania e regioni vicine. XXIV. Pesci. Annali del Museo Civico de Storia Naturale di Genova (Ser. 2a) 9: 129-362, pls. 7-11.

Vishwanath, W. (2000). Fishes Fauna of Manipur. Manipur Association for Science and Society, 137pp+VIpls.

Vishwanath, W., W. Manojkumar, L. Kosygin \& K.S. Selim (1998). Biodiversity of freshwater fishes of Manipur, India. Italian Journal of Zoology 65 (supplementary): 321-324.

Vishwanath, W., W.S. Lakra \& U.K. Sarkar (2007). Fishes of North East India. National Bureau of Fish Genetic Resources, Lucknow, UP., India, 264pp.

Author Details: A. DARSHAN is a Post-Doctoral Fellow of Department of Biotechnology, Govt of India and is at present attached to the Directorate of Coldwater Fisheries Research, Bhimtal, Uttarakhand. He is working on the phylogeny of catfishes based on classical and molecular techniques. W. VISHWANATH is a Professor in the Department of Life Sciences, Manipur University. His field of specialization is fish and fisheries. He is presently engaged in taxonomy and systematics of freshwater fishes of northeastern India. P.C. MAHANTA is the Director of Directorate of Coldwater Fisheries Research (DCFR), Bhimtal, Uttarakhand (under ICAR). He is presently engaged in various aspects of coldwater fishery including exploration and documentation of coldwater fishes of India. He is also supervising the Post doctoral research. A. BARAT is a Principal Scientist in DCFR, Bhimtal. His field of specialization is cytogenetics and fish molecular biology. He is presently engaged in the molecular characterization and phylogeny of Coldwater fishes of India. He also supervises doctoral and post doctoral research in fish and fisheries.

Author Contribution: The study: AD survey, collection, morphometric and anatomic study and phylogeny of catfishes of northeastern India; WV supervision of taxonomy and phylogeny of freshwater fishes of northeastern India; PCM Inventory and cataloguing of coldwater fishes of India; AB Supervise phylogenetic study of coldwater fishes.

Current paper: AD detailed examination of Mystus species of northeastern India and comparison with specimens in ZSI and in other museums and preparation of drawings; WV supervision in establishing new species and discuss taxonomic status; PCM supervision in identification of coldwater fish species interpretation of the result, and discuss taxonomic status; $\mathrm{AB}$ Differential diagnosis, interpretation of the results, comparison with available literature and discuss taxonomic status. 